\title{
PENGARUH KECERDASAN DAN BUDAYA ETIS ORGANISASI TERHADAP PRILAKU ETIS AUDITOR DI PROVINSI BALI
}

\author{
Luh Putu Normadewi A.P Ni Putu Riasning* Luh Kade Datrini \\ Fakultas Ekonomi Universitas Warmadewa, Denpasar, Bali \\ *E-Mail: riasning@yahoo.com
}

\section{Abstract}

The aim of this research is to explain the influence of Emotional Intelligence, Locus of Control and Ethical Culture of Organization to Ethical Behavior of Auditor in Bali Province. The research method is survey method. The data used consist of primary data and secondary data. This study used 65 respondents determined by using purposive sampling. This research uses multiple linear regression analysis techniques with simultaneous test and partial test with the program SPSS for window version 21.

The result of the research with multiple regression test shows that by using simultaneous test of Emotional Intelligence, Locus of Control and Ethical Culture of Organization have positive and significant influence to Ethical Behavior of Auditor. And based on the partial test indicates that the variables of Emotional Intelligence, Locus of Control and Ethical Culture of Organization have a positive and significant influence to EthicalBehavior of Auditor in Bali Province

\section{Keywords: Emotional intelligence, Locus of control, Organization Ethical Culture and ethics.}

\begin{abstract}
Abstrak
Tujuan dari penelitian ini adalah untuk mengetahui pengaruh Kecerdasan Emosional, Locus of Control dan Etika Budaya Organisasi terhadap Perilaku Etis Auditor di Provinsi Bali. Metode penelitian yang digunakan adalah metode survei. Data yang digunakan terdiri dari data primer dan data sekunder. Penelitian ini menggunakan 65 responden yang ditentukan dengan menggunakan purposive sampling. Penelitian ini menggunakan teknik analisis regresi linier berganda dengan uji simultan dan uji parsial dengan program SPSS untuk window versi 21.

Hasil penelitian dengan uji regresi berganda menunjukkan bahwa dengan menggunakan uji simultan kecerdasan emosional, Locus of Control dan Etika Budaya Organisas berpengaruh positif dan signifikan terhadap Perilaku Etis Auditor. Dan berdasarkan uji parsial menunjukkan bahwa variabel Kecerdasan Emosional, Locus of Control dan Etika Budaya Organisasi memiliki pengaruh positif dan signifikan terhadap Perilaku Etis Auditor di Provinsi Bali.
\end{abstract}

\section{Kata kunci: Kecerdasan Emosional, Locus of Control, Etika Budaya Organisasi.}

\section{PENDAHULUAN}

Audit merupakan suatu jasa yang diberikan oleh seorang profesional dibidang akuntansi untuk memberikan suatu evaluasi atau pemeriksaan terhadap laporan keuangan perusahaan.Dalam

praktiknya, perusahaan melakukan audit sebagai pengawasan di intern perusahaan yang dilakukan oleh seorang auditor internal, selain itu pihak perusahaan juga membutuhkan audit dari pihak eksternal perusahaan yang dilakukan oleh auditor independen.

Kasus Enron yang melibatkan salah satu kantor akuntan public The Big Five . serta berbagai kasus serupa yang terjadi di Indonesia seperti kasus PT Kimia Farma (2001)PT Great River International
Tbk (Great River) (2003PT Myoh Technology Tbk (2005) (Hukumonilne.com 2007),meskipun dengan bentuk yang berbeda, penekanan pentingnya etika profesi khususnya bagi professional di bidang akuntansi semakin menjadi sorotan. Perhatian terhadap pentingnya etika ini dilakukan mengingat kasus tersebut tidak lepas dari akibat diabaikannya masalah etika profesi (Santoso, 2008) yang menimbulkan citra yang negatif terhadap profesi akuntan publik. Hal ini tentu saja akan merusak citra profesi akuntan di masyarakat yang pada akhirnya menurunkan kepercayaan masyarakat terhadap profesi akuntan

Perilaku tidak etis merupakan isu yang relevan 
bagi profesi akuntan saat ini Isu mengenai etika akuntan di Indonesia berkembang seiring dengan terjadinya beberapa pelanggaran etika, baik yang dilakukan oleh akuntan publik, akuntan Internal maupun akuntan pemerintah (Ludigdo, 1999).

Berbagai penelitian tentang etikabaik etika profesi akuntan maupun etika bisnis memberikan bukti empiris mengenai faktor-faktor yang mempengaruhi sikap dan perilaku etis seseorang (dalam hal ini akuntan, mahasiswa, manajer, karyawan, dan salesmen) yang dapat dikelompokkan ke dalam tiga aspek, yaitu: 1) Aspek individual; 2) Aspek organisasional; dan 3) Aspek lingkungan. ( Ridwan Tikolah,at,al (2006)

Penelitian tentang etika yang menyatakan berbagai faktor yang mempengaruhi sikap dan perilaku etis seseorang antara lain yang telah dilakukan oleh Ridwan Tikolah2 at all (2006), Jurica dan Gunardi, (2012), Arianti (2012), Astriana, (2014), Maryani \& Ludigndo, (2008), Riasning, (2016), Nurul istiqamah (2016), Aprillilawati dan Alit suardana (2016).

Penelitian ini difokuskan pada aspek individual dan organisasi yang mempengaruhi Prilaku etis Auditor di Provinsi Bali. Penelitian ini dimotivasi oleh penelitian Ridwan Tikolah (2006),yang menujjukkan hanya variable intelektual yang berpengaruh nyata terhadap sikap etis mahasiswa, Jurika dan Gunardi (2012) yang menunjukkan hanya kecerdasan emosional yang berpengaruh nyata terhadap sikap etis mahasiswa sedangkan kecerdasan spiritual dan locus of control tidak berpengaruh, Arianti (2012) Locus of contol pengaruhnya berbeda antara internal dan ekternal, Astriana (2014) menunjukkan mahasiswa memahami kode etik akuntan tapi belum memahami standar khusus tentang hadiah, Nurul istiqamah (2016) menunjukkan budaya etis organisasi tidak berpengaruh terhadap sikap etis, Riasning (2016) yang menunjukkan kecerdasan yang paling dominan berpengaruh adalah kecerdasan spiritual, Aprillawati dan Alit suardana (2016) menunjukkan Budaya etis organisasi berpengaruh positif pada pertimbangan etis auditor.

Penekanan penelitian ini pada dimensi Kecerdasan emosional (EQ), Locus of control (LC) dan Budaya etis organisasal (ECO) yang mempengaruhi prilaku etis Auditor (EBA).

Kecerdasan emosional (EQ) adalah kemampuan mengetahui perasaan sendiri dan perasaan orang lain, serta menggunakan perasaan tersebut menuntun pikiran dan perilaku seseorang (Salovey dan Mayer, 1990 dalam JuriCa dan Gunardi ,2012).

Locus of control adalah cara pandang seseorang terhadap suatu peristiwa dimana seseorang apakah dapat/tidak dapat mengendalikan peristiwa yang terjadi padanya(Robbins, 2006:132) dalam (JudiCa dan Gunardi,2015).

Budaya etis organisasi adalah system makna dan keyakinan bersama yang di anut oleh para anggota organisasi yang menentukan sebagian besar cara mereka bertindak, budaya tersebut mewakili persepsi bersama yang dianut oleh para anggota organisasi tersebut (Robbins, 2006:58) dalam (Nurul istiqamah, 2016). Budaya organisasi pada intinya merupakan sebuah sistem dari nilai-nilai yang bersifat umum.Persepsi terhadap budaya organisasi didasarkan pada kondisi-kondisi yang dialami seseorang dalam organisasinya, seperti penghargaan, dukungan, dan perilaku yang diharapkan diperoleh di organisasi.

Berbagai ungkapan tentang penelitian di atas memberikan gambaran kecerdasan emosional, locus of control dan budaya etis organisasi berpengaruh terhadap sikap atau perilaku etis seseorang.

Berdasarkan latar belakang diatas, maka yang menjadi rumusan masalah dalam penelitian ini adalah: .Apakah Kecerdasan Emosianal, Locus of control dan Budaya etis organisasi berpengaruh terhadap Perilaku Etis Auditor baik secara simultan maupun parsial

\section{TINJAUAN PUSTAKA DAN HIPOTESIS A. TINJAUAN PUSTAKA \\ 1. Pengertian Kecerdasan}

Binet seorang psikologis Prancis (dalam Ridwan Tikolah 2006), mengatakan bahwa kecerdasan adalahkemampuan untuk menetapkan dan mempertahan suatu tujuan untuk mengadakanpenyesuaian dalam rangka mencapai tujuan untuk bersikap kritis terhadap diri sendiri

\section{Kecerdasan Emosional (EQ)}

Kecerdasan emosional adalah kemampuan mengenali perasaan diri sendiri dan perasaan orang lain, memotivasi diri sendiri, serta mengelola emosi dengan baik pada diri sendiri dan dalam hubungan dengan orang lain. Goleman (2005: 512)

Golemen (2005: 93) mengadaptasi model Salovey-Meyer membagi kecerdasan emosional ke dalam lima unsur yang meliputi:

a) Kesadaran diri atau pengenalan diri, pada dasarnya berupa pemahaman diri untuk mengetahui kondisi diri sendiri, pengetahuan tentang perasaan sebenarnya pada suatu kejadian,kesukaan, sumber daya dan institusi, seperti: kesadaran emosi, penilaian diri secara teliti dan percaya diri.

b) Manajemen diri atau pengaturan diri atau pengendalian diri memberi tekanan pada mengelola kondisi, impuls dan sumber daya diri sendiri, peka terhadap kata hati 
dan sanggup menunda kenikmatan sebelum tercapainya suatu sasaran, mampu pulih kembali dari tekanan emosi, seperti: menangani emosi untuk memudahkan, kendali diri, sifat dapat dipercaya, kewaspadaan, adaptibilitas dan inovasi.

c) Motivasi diri yaitu tetap pada tujuan yang diinginkan, kecenderungan emosi yang mengantar atau memudahkan peralihan sasaran, dan bertahan menghadapi kegagalan dan frustasi, seperti: dorongan prestasi, komitmen, inisiatif dan optimisme.

d) Empati merupakan kesadaran terhadap perasaan, kebutuhan dan kepentingan orang lain, merasakan yang dirasakan oleh orang lain, seperti: memahami orang lain, orientasi pelayanan, mengembangkan orang lain, mengatasi keragaman dan kesadaran politis.

e) Keterampilan sosial yaitu kemampuan membaca situasi sosial, berinteraksi dengan orang lain dan membentuk jaringan, kepintaran dalam menggugah tanggapan yang dikehendaki pada orang lain, seperti: pengaruh, komunikasi, kepemimpi -nan, manajemen konflik, pengikat jaringan, kolaborasi dan

\section{Locus Of Control}

Robbins dan Judge (2008) mendifinisikan locus of control sebagai tingkat dimana individu yakin bahwa mereka adalah penentu nasib mereka sendri (Basudewa ,2015). Locus of control dibedakan menjadi 2 yaitu locus of control internal dan locus of controleksternal (Robbins, 2006:132) dalam (Aini.2015). Dinyatakan juga bahwa situasi dimana individu -individu dengan lokus kendali eksternal merasa tidak mampu dalam mendapatkan dukungan kekuatan yang dibutuhkannya untuk bertahan dalam suatu organisasi, maka mereka akan memiliki potensi untuk mencoba memanipulasi rekan atau objek lainnya sebagai kebutuhan pertahanan mereka (Aini 2015).

\section{Budaya Etis Organisasi}

Budaya Etis Organisasi pada intinya merupakan sebuah sistem dari nilai-nilai yang bersifat umum. Adapun nilai-nilai personal mulai dikembangkan pada saat awal kehidupan, seperti halnya kepercayaan pada umumnya, tersusun dalam sistem hirarkidengan sifat-sifat yang dapat dijelaskan dan diukur, serta konsekuensi-konsekuensiperilaku yang dapat diamati (Douglas et.al, 2001).

Sistem nilai umum yang dijelaskan oleh Ouchi $(1919,1980)$ adalah bagian dari kese- luruhan budaya organisasi. Nilai-nilai tersebut merupakan inti dari budayaorganisasi yang tercermin dalam praktek organisasi. Persepsi terhadap budayaorganisasi didasarkan pada kondisi-kondisi yang dialami seseorang dalam organisasinya, seperti penghargaan, dukungan, dan perilaku yang diharapkan diperoleh di organisasi.

Teori-teori sosio-psikologi awal, tentang sistem kepercayaan menjelaskan perubahan nilai sebagai proses kognitif, yaitu bentuk dari kebutuhan dasar manusiaterhadap konsistensi kognitif seseorang. Teori-teori sosio-psikologi sekarang ini mengasumsikan bahwa perubahan nilai merupakan proses afektif, bentuk dari kebutuhan akan kepuasan dirinya yang akan terpenuhi melalui seseorang yang memiliki kompetensi dan moralitas. Perspektif kognitif maupun afektif, keduanya konsisten dengan beberapa studi yang direview oleh Grube et. al (1994).

Sosialisasi dapat dikonsepkan sebagai suatu proses yang terdiri atas tiga tahap; prakedatangan, perjumpaan dan metamorfosis (Maneen dan Schein, 1977). Tahap pra kedatangan meliputi semua pembelajaran yang terjadi sebelum seorang anggota bergabung dengan organisasi itu. Dalam tahap perjumpaan, aparatur baru tersebut akan melihat seperti apakah organisasi itu sebenarnya dan kemungkinan bahwa harapan dan kenyataan dapat berbeda. Dalam tahap metamorfosis ini dimana seorang aparatur baru menyesuaikan diri pada nilai dan norma kelompok kerjanya.

Ponemon dan Glazer (1990) menyarankan bahwa sosialisasi di profesi akuntansi pada kenyataanya berawal dari sejak masa kuliah, dimana merekaditanamkan perilaku dan nilainilai profesional. Ponemon (1990, 1992) mengkonfirmasikan adanya mekanisme seleksi dan sosialisasi untuk mengontrolalasan etis pada akuntan publik.

\section{Perilaku Etis}

Menurut Ricky W. Griffin dan Ronald J. Ebert (2006:58) perilaku etis adalah perilaku yang sesuai dengan norma-normasosial yang diterima secara umum sehubungan dengan tindakan-tindakan yang benar dan baik..Perilaku etis adalah perilaku yang beretika dalam organisasi untuk pelaksanakan tindakan secara adil sesuai hukum konstitusional dan peraturan pemerintah yang dapat diaplikasikan.

Sedangkan menurut Mega Febrianti dalam artikelnyatentang Perilaku Etis dan Tanggung Jawab Sosial, yang ditulispada Minggu, 09 Desember 2012: menyatakan Perilaku Etis adalah berkaitan dengan atau berurusan dengan 
moral atau prinsip-prinsip moralitas, berkaitan dengan benar dan salah dalam perilaku. Etis berarti yang sesuaidengan aturan standar. Perilaku yang benar, khususnya standar profesi. Jadi, Perilaku etis adalah tindakan yang secara etis dapat membedakan mana yang benar dan salah sesuai dengan aturan-aturan moral yang berlaku. Perilaku etis ini dapat menentukan kualitas individu(karyawan) yang dipengaruhi oleh faktor - factor yang diperoleh dari luar yang kemudian menjadi prinsip yang dijalani dalam bentuk perilaku.

Menurut Dougall dalam Zulfahmi (2005) faktor-faktor yang mem-pengaruhi perilaku seseorang meliputi: Faktor personal, yaitu faktor yang berasal dari dalam individu, faktor situasional, yaitu faktor yang berasal dari luar dirimanusia sehingga dapat mengakibatkan seseorang cenderung berperilaku sesuai dengan karakteristik kelompok atauorganisasi di mana ia ikut di dalamnya, faktor stimulasi yang mendorong dan meneguhkan perilakuseseorang.

Dengan demikian dalam kaitan dengan etika profesi, sikap dan perilaku etis merupakan sikap dan perilaku yang sesuai dengan etika profesi tersebut.

\section{Kode Etik dan Profesi Akuntan}

Etika merupakan filsafat atau pemikiran kritis dan mendasar tentang ajaran-ajaran dan pandangan-pandangan moral. Etika meliputi suatu proses penentuan yang kompleks tentang apa yang harus dilakukan seseorang dalam situasi tertentu yang disifati oleh kombinasi dari pengalaman dan pembelajaran masingmasing individu .

Etika meliputi suatu proses penentuan yang kompleks tentang apa yang seharusnya dilakukan seseorang dalam situasi tertentu yang disifati oleh kombinasi dari pengalaman dan pembelajaran masing-masing individu (Ward et al., 1993 dalam Tikollah dkk, 2006).

Profesi adalah suatu pekerjaan yang mellaksanakan tugasnya memerlukan atau menuntut keahlian, menggunakan teknik-teknik ilmiah serta dedikasi yang tinggi.

Ikatan Akuntansi Indonesia (IAI) sebagai organisasi profesi di bidang akuntansi di Indonesia memiliki Kode Etik yang mengikat para anggotanya. Kode Etik IAI sebagaimana ditetapkan dalam Kongres VIII IAI di Jakarta pada tahun 1998 terdiri dari tiga bagian, yaitu: a) Prinsip Etika, b) Aturan Etika, dan c) Interpretasi Aturan Etika. Kode Etika IAI tersebut menekankan pentingnya prinsip etika bagi para akuntan dalam melakukan kegiatan profesionalnya. Prinsip Etika dalam Kode Etik IAI terdiri dari delapan, yakni: (1) Tanggung jawab profesi, (2) Kepentingan publik, (3) Integritas, (4) Obyektivitas,
(5) Kompetensi dan kehati-hatian professional, (6) Kerahasiaan, (7 Perilaku professional, dan (8) Standar teknis.

\section{Hasil peneliti sebelumnya}

Penelitian tentang etika yang dilakukan Ridwan Tikolah et,al,(2006) tentang pengaruh kecerdasan, intelektual, emosional dan spiritual terhadap sikap etis mahsiswa. Hasil penelitian menunjukkan bahwa hanya kecerdasan intelektual yang berpengaruh nyata terhadap sikap eris mahasiswa,

Penelitian yang dilakukan oleh Jurica dan Gunardi (2012) tentang factor-faktor yang mempengaruhi sikap etis mahasiswa. Hasil penelitian menunjukkan hanya keceerdasan emosional yang berpengaruh terhadap sikap etis mahasiswa sedangkan locus of control dan jender tidak berpengaruh.

Penelitian yang dilakukan oleh Arianti (2012), tentang perbedaan pengaruh locus of control dan gender . Hasil penelitian menunjukkan pengaruh $h$ lacus of control berbeda antara internal dan ekternal, gender antara laki dan perempuan juga berpengaruh nyata.

Penelitian yang dilakukan oleh Maryani \&Ludigno(2008) tentang pengaruh kecerdasan emosional (emotional quotient (EQ) terhadap sikap etis auditor. Hasil penelitian ada pengaruh kecerdasan emosional terhadap sikap etis auditor.

Peneltian yang dilakukan Riasning (2016) tentang pengaruh kecerdasan intelektual, emosional, spiritual terhadap sikap etis mahasiswa akuntanasi, Hasil penelitian ketiga variable tersebut berpengaruh secara nyata.

Penelitian yang dilakukan oleh Nurul Istiqamah (2016) tentang Pengaruh Kecerdasan intelektual, emosional, spiritual dan budaya organisasi terhadap sikap etis mahasiswa. Hasil penelitian kecerdasan emosional, dan budaya organisasi tidak berpengaruh terhadap sikap etis mahasiswa Penelitian yang dilakukan oleh Aprillawati dan Alit Suardana (2016), tentang budaya etis organisasi sebagai variable pemoderasi pengaruh orientasi etis pada pertimbangan etis auditor. Hasil penelitian Budaya etis berpengaruh terhadap pertimbangan etis auditor sebagai mediasi.

\section{B. Pengembangan Hipotesis}

Berdasarkan berbagai uraian di atas dapat dirumuskan hipotesis sebagai berikut :

1) $\mathrm{H}_{1}$ : EQ, LC dan ECO berpengaruh signifikan terhadap perilaku etis auditor

2) $\mathrm{H}_{2}$ : EQ berpengaruh positip signifikan terhadap perilaku etis auditor

3) $\mathrm{H}_{3}$ : LCberpengaruh positip signifikan terhadap 
perilau etis auditor

4) $\mathrm{H}_{4}:$ ECO berpengaruh positip signifikan terhadap perilaku etis auditor.

\section{III.METODE PENELITIAN}

Penelitian ini dilakukan di KAP yang ada di provinsi Bali dengan mengambil sampel sebanyak 65 orang auditor dengan kreteria yang memiliki pengalaman kerja lebih dari setahun dengan menggunakan teknik purposive sampling

\section{Identifikasi Variabel}

a) Kecerdasan Emosional (EQ)

b) Locus of Control ( LC)

c) Budaya Etis Organisasi (ECO)

\section{Difinisi Operasional}

a) Perilaku Etis Auditor (EBA) adalah Respon auditor terhadap kejadian yang mengandung situasi dilematis berdasarkan Prinsip Etika Kode Etik IAI. (Ridwan Tikolah, 2006) Variabel ini diperoleh dengan kuesioner yang terdiri dari tujuh item kejadian yang mengadung situasi dilematis dari perspektif Prinsip Etika Kode Etik IAI.Indikatornya adalah: (1) Tanggung jawab profesi, (2) Kepentingan Publik, (3) Integritas, (4) Obyektivitas, (5) Kompetensi dan kehati-hatian, (6) Kerahasiaan), (7) Prilaku profesionalisme .Variabel ini diperoleh dari kuisioner dengan 25 pertanyaan, yang pengukurannya dengan skor 1-5

b) Kecerdasan Emosional (EQ), adalah kemampuan auditor untuk mengenali perasaan diri sendiri dan perasaan orang lain, memotivasi diri sendiri, serta mengelola emosi dengan baik pada diri sendiri dan dalam hubungan dengan orang lain (Goleman,2005: 512 dalam Riasning, 2016). Indikatornya adalah (1) Pengenalan diri), (2) Pengendalian diri ( control diri, dapat dipercaya, berhati-hati, adaftabilitas, inovasi), (3)Motivasi (dorongan berprestasi, komitmen, inisiatif, optimisme),(4) Empaty (memahami orang lain, mengembangkan orang lain, orientasi pelayanan), (5) Keterampilan social (pengaruh, komonikasi, manajemen konflik, kepemimpinan, membangun ikatan, kalaborasi dan kooprasi, kemampuan tim. Variabel ini diperoleh dengan kuesioner yang terdiri dari 24 pertanyaan yang diadaptasi dari Ridwan Tikolah (2006), yang pengukurannya menggunakan kuisnare dengan skor 1-5

c) Locus Of Control (LC)adalah cara pandang seorang auditor terhadap suatu peristiwa dimanan seseorang apakah dapat/tidak dapat mengendalikan peristiwa yang terjadi padanya.
(Robbins, 2006:132) dalam (Aini 2015).Indikator yang digunakan dalam pengukuran locus of control adalah sebagai berikut: Memperoleh pekerjaan adalah keberuntungan, Faktor koneksi dan keahlian dalam memperoleh jabatan dan pekerjaan,Promosi jabatan merupakan nasib baik, Jumlah penghasilan yang diperoleh tergantung pada keberuntung-an. yang pengukurannya menggunakan kuisnaire dengan skor 1-5.

d) Budaya Etis Organisasi (ECO) suatu pandangan tentang persepsi auditor atas tindakan etis pimpinan yang memperhatikan pentingnya etika didalam perusahaan.Budaya etis organisasi diukur dengan 3 indikator yang dikembangkan oleh Hunt et al. (1989). Setiap butiran pertanyaan mengandung tindakan - tindakan yang dilakukan oleh pimpinan terhadap bawahannya baik yang sikap etis maupun tidak etis. Indikator dalam budaya etis organisasi (Fallah, 2007) yaitu gaya kepemimpinan atasan, hukuman atas tindakan atau perilaku tidak etis dalam organisasi akan memperbaiki diri dan bersikap etis, kompromi atas perilaku tidak etis tidak di benarkan.

\section{Jenis Data Yang Digunakan}

Sumber data adalah primer dengan menyebarkan angket kuisner ke masing- masing kantor akuntan publik yang ada di Provinsi Bali sesuai dengan responden yang telah ditentukan. dan data skunder adalah data yang diperoleh dari KAP. Sifat data adalah kuantitatif dan kualitatif (scoring).

\section{Metode Pengumpulan Data}

a) Metode kuisioner, pengumpulan data ini dilakukan dengan melakukan tanya jawab langsung pada responden sesuai dengan isi kuisner ke kantor akuntan publik, kemudian diisi saat itu juga yang lama pengumpulannya diperkirakan selama 30 hari .

b) Dokumentasi, adalah berupa buku- buku dan hasil penelitian sebelumnya serta jumlah akuntan publik yang menjadi sasaran dalam penelitian ini.

\section{Teknik Analisis Data}

\section{a) Validitas dan Uji Reliabilitas}

Instrumen penelitian yang digunakan dapat dievaluasi melalui uji validitas dan reliabilitas. dengan bantuan program SPSS ver 15 for windows

\section{b) Uji Asumsi Klasik}

Untuk mengetahui apakah hasil estimasi regresi yang dilakukan benar-benar bebas dari adanya gejala 
heteroskedastisitas, data normal dan gejala multikolinearitas. Model regresi dapat dijadikan alat estimasi yang tidak bias jika telah memenuhi persyaratan BLUE (best linear unbiased estimator)

\section{c) Uji Hipotesis}

Pengujian hipotesis dilakukan dengan menggunakan analisis regresi berganda (multiple regression analysis), dengan program SPSS ver 15 forwindowsdengan model sebagai berikut:

$\mathrm{Y}=\beta_{1} \mathrm{X} 1+\beta_{2} \mathrm{X} 2+\beta_{3} \mathrm{X} 3+\mathrm{e}$ (Ghozali Imam, 2013 : 21)

Atau $\mathrm{EBA}=\beta_{1} \mathrm{EQ}+\beta_{2 \mathrm{LC}}+\beta_{3 \mathrm{ECO}}+\mathrm{e}$

Keterangan:

EBA :Sikap Etis Mahasiswa Akuntansi

EQ : Kecerdasan Emosional

LC : Locus OF Control

ECO : Budaya Etis Organisasi

$\beta_{1}, \beta_{2}, \beta_{3}$ :Koefisien Regresi

e :Erorr

Hasil regresi linear berganda akan dilakukan Uji Signifikansi Simultan (Uji F). Uji F merupakan pengujian terhadap koefisien regresi secara bersamasama yaitu pengaruh dari seluruh variabel independen $(\mathrm{X} 1, \mathrm{X} 2, \mathrm{X} 3$ ) terhadap variabel dependen (Y). Sedangkan Uji Signifikansi Parameter Individual (Uji t) digunakan untuk menguji hipotesis secara parsial guna menunjukan pengaruh tiap variabel independen secara individu terhadap variabel dependen, yakni pengaruh EQ terhadap EBA, Pengaruh LC terhadap EBA dan Pengaruh ECO terhadap EBA.

\section{IV.HASIL DAN PEMBAHASAN}

\section{A. Hasil Uji Validitas dan Relibilitas}

Uji validitas instrument penelitian ini dilakukan terhadap instrument EQ, LC, ECO dan Prilaku etis (EBA). dengan bantuan program SPSS ver 21 for windows. Hasil uji validitas dan reliabilitas instrumen penelitian ini menunjukkan 24 item variable EQ, 15 item variable LC dan 8 item variabel ECO valid nilai $r<0,03)$. Sedangkan 24 item variabel EBA valid (nilai $r>0,03$ ), maka dapat disimpulkan semua butir pertanyaan dalam variabel penelitian ini adalah valid, menurut kriteria Ghozali ( 2013 ). (lampiran 3 )

Uji reliabilitas EQ, LC, ECO dan EBA dengan menggunakan SPSS ver 21 for windows terlihat hasil nilai koefisien Cronbach Alpha pada variabel nilainya lebih besar dari 0,6 , maka dapat disimpulkan semua butir pertanyaan dalam variabel penelitian ini adalah reliable,mMenurut kriteria Ghozali( 2013 ). ( lampiran 3 )

\section{B. Hasil Pengujian Asumsi Klasik}

Hasil pengujian asumsi klasik untuk normalitas menunjukkan nilai probabilitas Uji KolmogorovSmirnov (2-tailed p.) lebih besar dari 0,05 (0,568 > 0,05); nilai VIF EQ, LC, dan ECO lebih kecil dari 10 $(1,053 ; 1,341 ; 1,355<10)$; nilai Tolerance lebih besar dari $0,10(0,949 ; 0,746 ; 0,738>0,10)$ nilai $\beta$ Uji Park EQ, LC, dan ECO lebih besar dari 0,05 $(0,325 ; 0,138 ; 0,272>0,05)$; Hal ini berarti data penelitian ini berdistribusi normal serta tidak terjadinya multikolinearitas dan heteroskedastisitas, menurut kriteria Ghozali( 2013).

\section{Hasil Pengujian Hipotesis}

Hasil pengujian hipotesis yang dilakukan dengan analisis regresi linear berganda menunjukkan nilai Sign Regresi dengan uji $\mathrm{F}$ lebih kecil dari 0,05 $(0,000<0,05)$; dengan uji $\mathrm{T}$ nilai Sign EQ lebih kecil dari $0,05(0,033<0,05)$, nilai Sign LC dan nilai Sign ECO lebih kecil dari 0,05 $(0,07 ; 0,048<$ $0,05)$, serta nilai standardized coefficien $\mathrm{EQ}, \mathrm{LC}$, dan ECO masing-masing 0,244; 0,251; dan 0,355 (Lampiran 3). Berdasarkan hasil pengujian tersebut dapat disimpulkan bahwa EQ, LC, dan ECO secara parsial dan simultan berpengaruh signifikan terhadap Prilaku etis auditor. variable EQ, LC dan ECO berpengaruh terhadap EBA, ini dapat dilihat dari nilai standardized coefficient masing - masing variable tersebut $(0,244,0,3251$ dan 0,355$)$

\section{Pembahasan}

Pengaruh EQ, LC dan SQ terhadap Prilaku Etis Auditor

Hasil penelitian ini menunjukkan bahwa EQ, LC, dan ECO secara simultan berpengaruh signifikan terhadap EBA

Demikian halnya dengan pengaruh secara parsial, hasil penelitian ini menunjukkan bahwa secara parsial baikEQ,LC maupun ECO berpengaruh signifikan terhadap Prilaku etis auditor Dengan demikian hasil penelitian ini secara mendukung apa yang dikemukan oleh Jurica dan Gunardi (2012), Jamaludin dkk (2014) dan Zohar \& Marshall (2008), Hasil penelitian ini juga mendukung penelitian Debora (2012), Riasning (2016), Ustadi dan Utami (2005), dan Hastuti (2007) penelitian yang dilakukan oleh Aprillawati dan Suardana (2016)

\section{DAFTAR PUSTAKA}

agoes, Sukrisno. Auditing Petunjuk Praktis Pemeriksaan Akuntan oleh Akuntan Publik Edisi 4Buku 1. Jakarta: Salemba Empat, 2014.

Amstrong, Thomas. 2009. 7 Kinds of Smart. Menemukan dan Meningkatkan Kecerdasan Anda Berdasarkan Teori Multiple Intelligence. Jakarta: GramediaPustaka Utama. 
Ghozali, Imam, (2013), “Aplikasi Analisis Multivariate dengan program IBM SPSS 21", Badan Penerbit Universitas Diponegoro, Semarang.

Mulyadi, dan Kanaka,(2013), Auditing Pendekatan Terpadu, Salemba Empat. Jakarta.

Paulus, Silvia Veronika, (2012), Struktur Organisasi Kantor Akuntan Publik, http:// captainvie.blogspot.com

Sugiyono, (2016), Statistika Untuk Penelitian, Alfabeta, Bandung.

Wirawan, ( 2009), Konflik dan Manajemen Konflik, Salemba Humanika: Jakarta

Aji, Bima Bayu, (2010), Analisis Dampak Dari Locus Of Control pada Tekanan Kerja, KepuasanKerja, dan Kinerja Auditor Internal, Tesis Jurusan Akuntansi, Universitas Diponegoro, Semarang.

Aprilliawati, alit Suardana (2016), Budaya etis organisasi sebagai variable Pemoderasi pengaruh orientasi etis pada pertimbangan etis auditor

Basudewa, Dewa Gede Agung. (2015) Pengaruh Locus Of Control, Komitmen Organisasi, Kinerja Auditor, dan Turnover Intention pada Prilaku Menyimpang dalam Audit.

David. skandal-manipulasi-laporan-keuangan-ptkimia-farma-tbk/. november 4,2009. https:// davidparsaoran.wordpress.com/2009/11/04/ skandal-manipulasi-laporan-keuangan-ptkimia-farma-tbk/.

Dwirandra. (2013). "Pengaruh Perilaku Belajar terhadap Tingkat PemahamanAkuntansi dan Sikap Etis dengan Kecerdasan Emosional dan Kecerdasan Spiritualsebagai Variabel Pemoderasi."Bisnis. Jurnal Riset Akuntansi Indonesia. Vol. 1 No. 2, hlm. 1-19.

Fanani, Zaenal, (2008), Pengaruh Struktur Audit, Konflik Peran, dan Ketidakjelasan Peran terhadap Kinerja Auditor, Jurnal Akuntansi dan Keuangan Vol 5 No 2, Universitas Airlangga Surabaya, Surabaya, hal 139- 155.

Fatmawati, N.D (2007), Analisis Pengaruh FactorFaktor Individual Terhadap Prilaku Auditor di KAP Yogyakarta Riset ekonomi
Gunawan, dan Ramdan, ,(2010), Pengaruh Konfik Peran, Ketidakjelasan Peran, dan Gaya Kepemimpinan terhadap Kinerja Auditor di Kantor Akuntan Publik Wilayah DKI Jakarta, Jurnal Ilmiah Jurusan Akuntansi, UniversitasBina Nusantara, Jakarta.

Hastuti,S (2007), Prilaku Etis Mahasiswa dan Dosen Ditinjau dari Factor-Faktor Individual Gender dan Locus of Control . Jurnal Rset Ekonomi dan Busnis Vol 7, Maret 58-73

Martina Made Bela dg Kawan-kawan,(2015), Pengaruh budaya Etis, orientasi Etika, Pengalaman, dan Profesionalisme Terhadap Sensitivitas Kegiatan Audit yang dilaksanakan Inspektorat Pemerintah Kabupaten Buleleng

Nurul istiqmah (2016), Pengaruh kecerdasan emosional, spiritual dan budaya organisasi terhadap prilaku etis mahasiswa akuntansi ,Jurnal riset ekonomi Muhamadyah Yogyakarta

Ridwan Tikolah, Iwan Tryuwono, H,Unti Ludigdi (2006). Pengaruh Kecerdasan Intelektual, Kecerdasan Emosional dan Spiritual terhadap Skap Etis Akuntan Publik di Makasar,Simposium ANasional Akuntansi 9 di Padang

Santoso, K2002 Dampak Kebangkrutan Enron Terhadap Citra Profesi Akuntan Publik, Media Akuntansi 25 (April) :17-19

Sumirat, Gunawan Cahya, (2006), Pengaruh Profesionalisme dan Komitmen Organisasi terhadap Kinerja Internal Auditor, dengan Kepuasan Kerja sebagai Variabel Intervening, Universitas Diponegoro, Semarang.

Suryaningsih ,S.S Heriningsih \&A Afwah. 2004 Pengaruh Pendidikan Tinggi Terhadap EQ. Proceeding Simposium Nasional Akuntansi VII. Denpasar 2-13 Desember , 351-369

Ustadi, N.H\&Utami R.D (2005). Analisis Perbedaan Factor-Faktor Individual Terhadap Persepsi Prilaku Etis Mahasiswa. Jurnal Akuntansi \&Auditing, Volume 01/N0.02 Mei 162-180

\section{Lampiran}

Tabel 1 Uji Validitas Variabel EQ

$\mathrm{N}=65$

\begin{tabular}{|c|l|c|c|c|}
\hline No & Indikator & r hitung & r tabel & Validitas \\
\hline 1 & EQ1 & 0,328 & 0.3 & Valid \\
\hline 2 & EQ2 & 0,425 & 0,3 & Valid \\
\hline 3 & EQ3 & 0,599 & 0,3 & Valid \\
\hline 4 & EQ4 & 0,456 & 0,3 & Valid \\
\hline 5 & EQ5 & 0,550 & 0,3 & Valid \\
\hline 6 & EQ6 & 0,588 & 0,3 & Valid \\
\hline 7 & EQ7 & 0,589 & 0,3 & Valid \\
\hline 8 & EQ8 & 0,308 & 0,3 & Valid \\
\hline
\end{tabular}


Tabel 2 Uji Validitas Variabel LC

$N=65$

\begin{tabular}{|l|l|l|l|l|}
\hline No. & Indikator & r hitung & r tabel & Validias \\
\hline 1 & LC1 & 0,660 & 0,3 & Valid \\
\hline 2 & LC2 & 0,623 & 0,3 & Valid \\
\hline 3 & LC3 & 0,726 & 0,3 & Valid \\
\hline
\end{tabular}

Tabel 3 Uji Validitas Variabel ECO

$\mathrm{N}=65$

\begin{tabular}{|c|c|c|c|c|}
\hline No. & Indikator & r hitung & r tabel & Validitas \\
\hline 1 & ECO1 & 0,502 & 0,3 & Valid \\
\hline 2 & ECO2 & 0,612 & 0,3 & Valid \\
\hline 3 & ECO3 & 0,457 & 0,3 & Valid \\
\hline 4 & ECO4 & 0,702 & 0,3 & Valid \\
\hline
\end{tabular}

Tabel 4 Uji Validitas Variabel Prilaku ETIS(Y/EBA)

$\mathrm{N}=65$

\begin{tabular}{|c|c|c|c|c|}
\hline No. & Indikator & r hitung & r table & Validitas \\
\hline 1 & EBA1 & 0,429 & 0,3 & Valid \\
\hline 2 & EBA2 & 0,533 & 0,3 & Valid \\
\hline 3 & EBA3 & 0,346 & 0,3 & Valid \\
\hline 4 & EBA4 & 0,382 & 0,3 & Valid \\
\hline 5 & EBA5 & 0,423 & 0,3 & Valid \\
\hline 6 & EBA6 & 0,330 & 0,3 & Valid \\
\hline 7 & EBA7 & 0,412 & 0,3 & Valid \\
\hline 8 & EBA8 & 0,412 & 0,3 & Valid \\
\hline
\end{tabular}

Tabel 5 Uji Reliabilitas variabel

$\mathrm{N}=65$

\begin{tabular}{|c|c|c|c|c|}
\hline No & Variabel & Cronbach's Alpha & Nilai kritis/Standard & Reliabilita \\
\hline 1 & EQ & 0,68 & $>0,6$ & Reliabel \\
\hline 2 & LC & 0,727 & $>0,6$ & Reliabel \\
\hline 3 & ECO & 0,696 & $>0,6$ & Reliabel \\
\hline 4 & EBA & 0,628 & $>0,6$ & Reliabel \\
\hline
\end{tabular}

Tabel 6 Hasil Uji Multikolienaritas

\begin{tabular}{|c|c|c|}
\hline \multirow{2}{*}{ Model } & \multicolumn{2}{|c|}{ Collianerity statistic } \\
\cline { 2 - 3 } & Tolerance & VIF \\
\hline EQ & 0,949 & 1,053 \\
\hline LC & 0,746 & 1,341 \\
\hline ECO & 0,738 & 1,355 \\
\hline
\end{tabular}

Tabel 7 Hasil Uji Multikolienaritas

Coefficieñts

\begin{tabular}{|c|c|c|c|c|c|}
\hline \multirow[b]{2}{*}{ Mod } & \multicolumn{3}{|c|}{$\begin{array}{l}\text { nstandardizeandardize } \\
\text { Coefficients Oefficien }\end{array}$} & \multirow[b]{2}{*}{$t$} & \multirow[b]{2}{*}{ Sig. } \\
\hline & B & d. Erro & Beta & & \\
\hline \begin{tabular}{|ll}
1 & (Cons
\end{tabular} & .440 & 1.957 & & .225 & .823 \\
\hline X1 & -.040 & .040 & -.121 & -.992 & .325 \\
\hline X2 & .125 & .083 & .208 & 1.504 & .138 \\
\hline X3 & .100 & .090 & .154 & 1.109 & .272 \\
\hline
\end{tabular}

